\title{
THE "SIX-THREE-THREE PLAN" AT MT. VERNON, INDIANA
}

\author{
E. J. LLEWELYN \\ Superintendent of Schools, Mt. Vernon, Indiana
}

\section{PURPOSE}

In order to give better service to the community, the schools of Mt. Vernon, Indiana, have been reorganized on the six-three-three plan. By giving greater elective privileges, similar to those which have been given in the regular high school for several years past, it was the purpose of the school management to eliminate the large number of pupils who become discouraged and leave school in the seventh and eighth grades or at the end of the eighth grade. By organizing the junior high school in the same manner in which the senior high school is organized, the purpose was to eliminate the break which comes at the end of the eighth grade just when the pupil is ready to enter high school. By giving pupils who make a certain minimum grade in their work in the seventh grade an opportunity of electing Latin, German, algebra, or industrial history, the purpose was to supply a greater motivation for study in the seventh grade in order to secure the elective privileges in the eighth grade.

\section{PLAN OF ORGANIZATION}

The intermediate grades (Grades VB to VIA, inclusive) are assembled from all over the city in the Main Street Building, which had been used for grammar-school purposes. In this building the work is semi-departmental. One instructor teaches penmanship in all the rooms; another instructor teaches spelling in all the rooms; another teaches music and drawing in all the rooms; and another teaches history and hygiene in all the rooms. The regular supervisors of domestic science, manual training, and music and drawing visit this building once each week and supervise the work of the regular teachers in their respective subjects.

The junior high school, composed of Grades VII, VIII, and IX, has been assigned to the upper floor and the basement of the new 
Central School Building. In this building a large assembly room and eleven classrooms, besides the necessary offices, etc., are devoted to this work.

In the seventh grade no electives are allowed, with the exception of the industrial work (manual training, agriculture, sewing, cooking, music, and drawing). However, the pupils are told that, if they make a grade of 87 per cent or more on the average in Grades VIIB and VIIA, they will be allowed to elect other subjects. The course of study has been so organized in the seventh grade in English, in arithmetic, and in history, that all of the essentials in these subjects are covered when the pupil has completed Grade VIIA. As soon as any pupil has made an average, for two succeeding semesters, of 87 per cent or more in either one or all of the subjects indicated, he is allowed to elect Latin or German, algebra or industrial history, in the next succeeding half-year, provided that it is the wish of his parents that he do so. If he does not make a grade of 87 per cent or more, he is required to continue the work in those subjects in which he fails to make the given minimum percentage. The course of study is organized so that there is additional and practical work for the pupil in Grade VIII who fails to make the minimum grade. A pupil is given full high-school credit for such regular high-school subjects as he is permitted to elect to take in the junior high school.

In the eighth grade, all of the regular eighth-grade subjects are offered, both in Grade VIIIB and in Grade VIIIA, for such pupils as fail to make the minimum grade which permits them to elect the high-school subjects. Courses in Latin, German, algebra, and industrial history are also offered for the pupils who do succeed in making the minimum grade and whose parents permit them to elect these subjects.

In the ninth grade, the regular high-school subjects are offered with the usual elective privileges.

\section{RESULTS}

The results obtained since the reorganization of the school system as indicated above are very satisfactory. The new stimulus for study and attendance supplied by this scheme is very effective. 
It is rarely that a pupil leaves school in Grade VII or Grade VIII unless it is absolutely necessary because of illness.

The teaching work in Grades VB to VIA, inclusive, is very much more efficient than it was under the old régime. The teaching work in the junior high school is more efficient than was the teaching work in the Grades VII and VIII prior to the reorganization. The junior high-school teachers feel that they must reach the same standard of efficiency as that reached by the senior high-school teachers.

The pupils from Grades VIIIB and VIIIA who are permitted to take the high-school subjects seldom fail to make the high-school credit. They enter the classes with the regular ninth-grade pupils and, with but one or two exceptions, they have always made higher grades than the regular ninth-grade pupils.

This system of organization has taken care of the slow pupil, and, what is more important, probably, it has made a way for the bright pupil to forge ahead and to receive a proper amount of recognition for so doing. Owing to the fact that the eighth-grade pupils who succeed in making the minimum grade go into the classes with the regular ninth-grade pupils, no additional teaching force is necessary to handle the school under this plan of reorganization. In fact, there is one teacher less now in the force from Grade VIIB to Grade XIIA, inclusive, than there was two years ago.

\section{CONCLUSIONS}

There is no possible doubt that some form of reorganization in our school system is necessary if the public schools of our country are to serve the best interest of all the people. By some scheme or other, the break must come earlier in the course than formerly. The logical place for this break seems to be between Grades VI and VII, so far as our present knowledge of the situation goes. It is immaterial whether the six-three-three plan or the six-six plan is used. For Mt. Vernon, the convenience of our buildings seems to favor the six-three-three plan, as indicated above. Each community will have to solve this problem in the manner best fitted to serve the interests of all its people. In this matter of reorganization, as in all other school affairs, what will serve the needs of one community may not serve the needs of any other community. 